\title{
Team Leaders Matter in Knowledge Sharing: A Cross-Level Analysis of the Interplay between Leaders' and Members' Goal Orientations in the Ghinese Context
}

\section{Jiamin Zhang, ${ }^{1}$ Yi Wang, ${ }^{2}$ and Marina Yue Zhang ${ }^{3}$}

${ }^{1}$ The University of Melbourne, Australia, ${ }^{2}$ Tsinghua University, China, and ${ }^{3}$ Swinburne University of Technology, Australia

\begin{abstract}
This article investigates the impact of cross-level interplay between team members' and their leaders' goal orientations (learning, performance approach, and performance avoidance) on knowledge sharing using samples from design teams in two companies in China. Our results show that team leaders' learning goal orientation plays a critical moderating role. Specifically, team leaders' learning goal orientation strengthens the positive relationship between team members' learning orientation and knowledge sharing; positively moderates the relationship between team members' performance approach orientation and knowledge sharing; and weakens the negative relationship between team members' performance avoidance orientation and knowledge sharing. Team leaders' performance approach orientation demonstrates a positive moderating effect when there is congruence between the performance approach orientation of leaders and members. Finally, team leaders' performance avoidance orientation negatively moderates the relationship between team members' learning and performance approach orientation on knowledge sharing. This research enhances our understanding of the conditions under which knowledge sharing occurs among team members, using the lens of Trait Activation Theory.
\end{abstract}

KEYwORDs China, cross-level interplay, goal orientation, knowledge sharing, trait activation theory

\section{INTRODUGTION}

As the global economy becomes more knowledge-based, knowledge sharing becomes a significant tool by which employees learn to cope with complex tasks and companies compete successfully. Most tasks in a knowledge-based economy require collective effort and, therefore, knowledge sharing is essential in undertaking such tasks. Organizational knowledge creation integrates context, knowledge

Corresponding author: Marina Yue Zhang myzhang@swin.edu.au

C 2018 The International Association for Chinese Management Research 
assets, and knowledge creation processes (von Krogh, Nonaka, \& Rechsteiner, 2012), and knowledge sharing is an important platform for knowledge creation and mutual learning (Huber, 1991). Though knowledge sharing is an individual act determined by individual dispositions, the majority of the knowledge sharing literature focuses on macro (organizational, collective) level factors, paying insufficient attention to micro (individual, interpersonal) level factors (see, for example, Foss, Husted, \& Michailova, 2010 for a review).

In recent years, academic attention has shifted to examine goal orientation, an individual construct, in knowledge sharing (Matzler \& Mueller, 2011; Swift, Balkin, \& Matusik, 2010) and team creativity (Gong, Kim, Lee, \& Zhu, 2013). Goal orientation is an individual's dispositional or situational preferences in achievement and is typically conceptualized as being of two types: learning goal orientation and performance orientation (the latter being differentiated into performance approach orientation and performance avoidance orientation) (Payne, Youngcourt, \& Beaubien, 2007). A learning goal orientation emphasizes acquiring knowledge and enhancing competence; a performance approach goal orientation concentrates on gaining positive evaluations and outperforming others; and a performance avoidance goal orientation focuses on avoiding mistakes and unfavorable evaluations and performance outcomes (Elliot \& McGregor, 2001; VandeWalle, 1997). In their conceptual paper, Swift et al. (2010) argue that individuals with a learning orientation will be more likely to share knowledge. This proposition has been confirmed in Matzler and Mueller's (2011) empirical research, which showed a significant negative relationship between performance goal orientation and knowledge sharing. The underlying reasoning for these contrasting relationships is that while individuals with a learning orientation seek to share knowledge as a way of building their skills to deal with challenging situations, those who have a performance orientation regard knowledge sharing as a complex and risky activity and prefer to undertake behaviors which have a greater likelihood of a more certain and immediate return.

Goal orientation is an important trait, and recent research has shown that this trait can be activated by situational cues (Tett \& Burnett, 2003; Tett \& Guterman, 2000). In organizations, team leaders play a multi-functional role which has direct consequences on team members' activities and performance (Chen \& Kanfer, 2006); this is especially true in the Chinese context where high power distance dominates organizational behavior (Hofstede, 2001; Lau, Tse, \& Zhou, 2002). However, in the knowledge sharing literature, what has not been investigated is the critical role played by team leaders' own goal orientation in knowledge sharing. This research aims to fill this gap.

Indeed, from the trait activation theory (TAT), leaders' own goal orientations, among other cues, provide important situational cues in relation to the goal orientation traits of their team members, and their subsequent knowledge sharing activities (Matzler \& Mueller, 2011; Tett \& Burnett, 2003; Tett \& Guterman, 2000). Given team leaders' influence in team members' activities, in this study, we treat 
team leaders' goal orientation as a team-level variable, but team members' goal orientation and knowledge sharing as individual-level variables. Knowledge sharing is, therefore, defined as an individual's intention to, and behavior of, sharing task-related ideas, exchanging task-relevant information, and providing suggestions to members within and beyond the working team (e.g., Srivastava, Bartol, \& Locke, 2006). Through a cross-level model of the interplay between leaders' and team members' goal orientations, we explore how a leader's goal orientation moderates the relationship between the member's goal orientation and knowledge sharing. Our findings confirm that the leaders' goal orientation has a significant moderating effect on the relationship between team members' goal orientation and knowledge sharing. Specifically, knowledge sharing is enhanced when there is congruence between the learning or performance approach orientations of leaders and members; and when the leader has a learning orientation, irrespective of the member's orientation. Conversely, knowledge sharing is inhibited when the leader has a performance avoidance orientation, irrespective of the members' orientation; and when the leader has a performance approach orientation but the member has a learning orientation.

\section{THEORETICAL BAGKGROUND AND HYPOTHESES}

Inherently, knowledge, especially tacit knowledge, is a resource held by individuals (Nonaka \& Takeuchi, 1995; Nonaka \& von Krogh, 2009). In organizations, especially in the context of an increasingly knowledge-based economy, it is critical that knowledge is shared among organizational members. Knowledge sharing, then, '... is basically the act of making knowledge available to others in the organization' (Ipe, 2003: 341). The knowledge itself may be explicit (formulas, procedures and processes, routines, etc.) or tacit (experiences, ideas, know-how, skills, etc.), but nevertheless knowledge sharing can occur through interactions of individuals or mediated by organizational factors (Leonard \& Sensiper, 1998; Nonaka \& Takeuchi, 1995; Nonaka \& von Krogh, 2009). At its core, it is a social activity that is undertaken within a system where knowledge has value and in which the decision about whether to share knowledge is a matter of choice of individuals, influenced by potentially a multitude of factors (Wang \& Noe, 2010). Much of the literature on knowledge sharing, both conceptually (Bartol \& Srivastava, 2002; Ipe, 2003) and empirically has been directed at its antecedents (Foss et al., 2010). Among many factors, recent studies have focused on the goal orientations of individuals (Gong et al., 2013; Matzler \& Mueller, 2011; Swift et al., 2010) as antecedents with a direct effect on knowledge sharing.

The goal orientation construct has its origins in the educational psychology literature on achievement motivation and has attracted a great deal of both theoretical and empirical attention (Kaplan \& Maehr, 2007). An individual's goal orientation is one's motivational orientation affecting how one approaches, interprets, and responds to achievement situations (Dweck, 1986; Elliot \& Church, 1997). 
Two distinct orientations have been identified: a learning goal orientation and a performance goal orientation (Dweck, 1999). Individuals with a learning orientation seek to increase their knowledge, expertise, or skills in order to master a task, and value learning for its own sake. They believe that performance can be improved by effort. Their motivation is intrinsic, such that they are likely to invest effort and persevere to accomplish tasks even without extrinsic rewards. In contrast, the motivation of individuals who hold a performance orientation is extrinsic. Performance orientation individuals are of two types: those focused on gaining favorable judgments by demonstrating competence and outperforming others (a performance approach orientation); and those seeking to avoid negative judgments by not looking incompetent as a result of performing worse than others (a performance avoidance orientation) (VandeWalle, 1997). Thus, compared to performance goal orientation, which is more easily influenced by extrinsic factors, learning goal orientation is self-referent and related to intrinsic motivational factors and, thus, is less influenced by extrinsic factors (Donovan, Bateman, \& Heggestad, 2013). Though findings have sometimes been contradictory (Yeo, Loft, Xiao, \& Kiewitz, 2009), meta-analyses (e.g., Cellar, Stuhlmacher, Young, \& Fisher, 2011) have shown that learning orientation is positively correlated with job performance, performance avoidance orientation is negatively correlated with performance outcomes, but performance approach orientation has no clear correlation with performance outcomes. On its own, a learning orientation is strongly related to an individual's propensity to share knowledge with others in order to develop creative solutions to problems (Gong, Huang, \& Farh, 2009; Hirst, van Knippenberg, \& Zhou, 2009) while a performance avoidance orientation has consistently been negatively related to various measures of performance (Elliot \& Church, 1997; Elliot \& McGregor, 2001; Hirst, van Knippenberg, Chen, \& Sacramento, 2011; Skaalvik, 1997).

An on-going debate in the literature (see Donovan et al., 2013) centers on whether individual goal orientation is related to stable individual differences (as a trait) or is cued by various contextual factors (as a state). As Donovan et al. (2013: 118) point out, there is now a '...vast research literature demonstrating that goal orientation is both amenable to situational influence and [italics in original] stable over time'. Recent research has come to a consensus that, 'A goal orientation may be prompted by situational cues that signal the goals and behaviors that are desired, emphasized or rewarded in the context of a particular goal or collective' (Bunderson \& Sutcliffe, 2003: 553). The implication is that, '....an analysis of the interplay between individual and context is essential to predict the expression of individual dispositions' (Hirst et al., 2011: 626). A number of studies have examined the influence of situational factors on the relationship between goal orientation and performance, including task demands (Yeo et al., 2009), the quality of leader-member exchange (Janssen \& Van Yperen, 2004), and evaluation apprehension (Watson, Thompson, Rudolph, Whelan, Behrend, \& Gissel, 2013).

To examine the interplays of leader-member goal orientations, we adopt the trait activation theory (TAT), which posits that individuals analyze, respond to, 
and adjust their behaviors according to environmental conditions (Tett \& Burnett, 2003; Tett \& Guterman, 2000). Specifically, the analytical framework of TAT uncovers the complexities of how personality plays out in work environments, based on three important notions: '(1) personality traits are latent propensities to behave in certain ways, (2) traits are expressed as responses to trait-relevant situational cues, and (3) intrinsic satisfaction is gained from expressing one's traits' (Tett, Simonet, Walser, \& Brown, 2013). Tett et al. (2013: 74) also find evidence to support the idea '...that traits are expressed behaviorally to the degree that the situation offers opportunities for their expression'. In organizations, team leaders hold considerable power, including that involving evaluating and rewarding/punishing their team members and, as a result, they are likely to have a significant impact on whether those members do or do not express their traits (i.e., on how the member's particular goal orientation trait is activated) which, in turn, will influence whether performance objectives such as knowledge sharing are achieved (Bunderson \& Reagans, 2011). Therefore, leaders provide one of the most important trait-relevant situational cues in organizations. This is especially true in the Chinese context where team leaders play multiple roles, such as directing and facilitating team activities, lobbying for resources, creating and maintaining a positive team atmosphere, in addition to fulfilling other normal functions, such as evaluation and performance appraisal, allocation of resources and making recommendations for the promotion of team members.

Various moderating variables have been examined in relation to individual goal orientation and performance measures, including leadership related variables such as leader-member trust (Gong et al., 2013) and monitoring mechanisms (Watson et al., 2013). Attention has also been given to the relationship between the goal orientation of leaders and the goal orientation of the organizational sub-units they lead (Dragoni \& Kuenzi, 2012). However, no study has yet examined the fit between the goal orientation of a team member and that of the member's leader.

Since trait activation is ' ...the process by which individuals express their traits when presented with trait-relevant situational cues' (Tett \& Burnett, 2003: 502), the nature of those cues is of central importance. Tett and Burnett (2003) provide a taxonomy of functional trait-relevant situational cues: (1) demands (trait-relevant cues, responses to which contribute positively to performance); (2) distracters (trait-relevant cues, responses to which contribute negatively to performance); (3) constraints (factors limiting cues for trait expression); (4) releasers (factors countering constraints); and (5) facilitators (factors that are uniquely multiplicative in that they magnify trait-relevant cues that are already present). Fundamental to TAT is the notion of 'bidirectionality' - traits may correlate positively or negatively with performance depending on the situation (Tett et al., 2013: 77). Furthermore, mutual needs can be fulfilled because of mutual trait activation (Tett \& Murphy, 2002), where interpersonal compatibility emphasizes the opportunity for trait expression. 


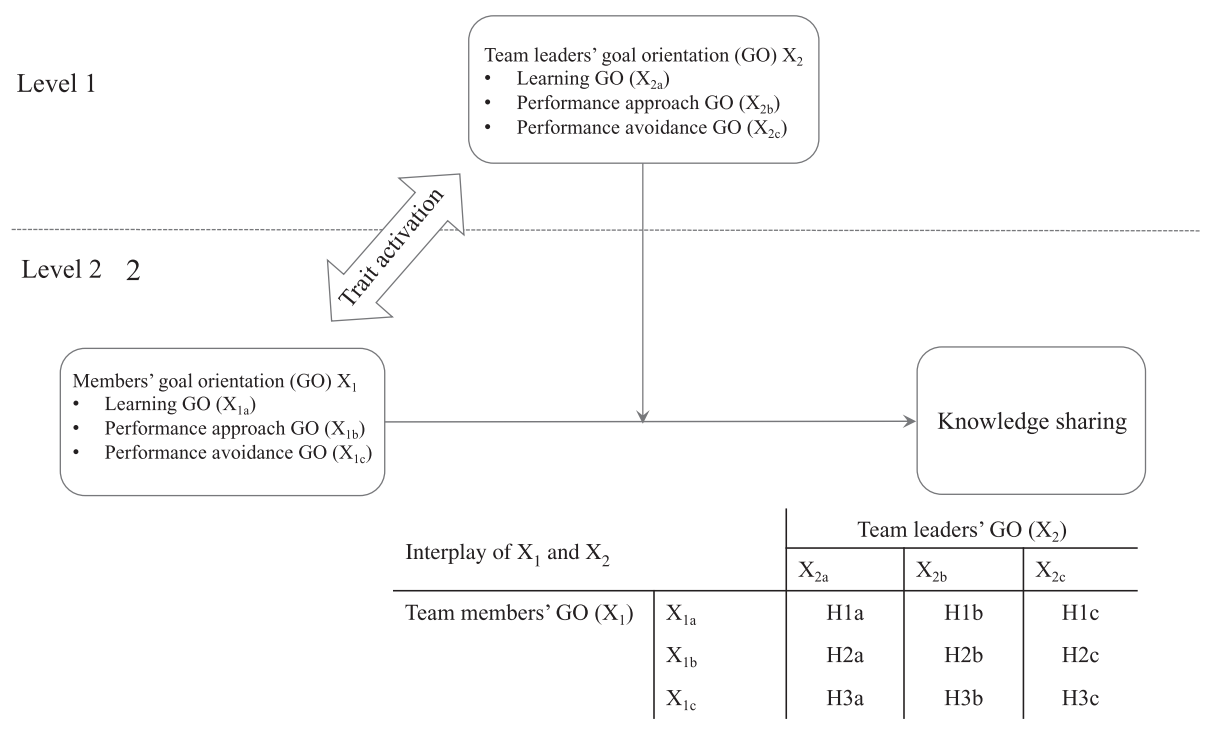

Figure 1. A multi-level model of knowledge sharing

Using the TAT framework, the central research question addressed in this article is the way in which a leader's goal orientation moderates the relationship between the team member's goal orientation and knowledge sharing. Specifically, we investigate the interplays of team leaders' and members' goal orientations and their influence on knowledge sharing of team members. In the following section, we develop hypotheses for each of the nine possible combinations of leadermember goal orientation interplay (learning, performance approach, or performance avoidance $\mathrm{x} 3$ ) in relation to knowledge sharing. Figure 1 depicts our theoretical model.

\section{The Interplay of Learning-Oriented Team Members and Leader's Goal Orientation}

Early studies (e.g., Dweck, 1986; Elliot \& McGregor, 2001; VandeWalle, 1997) of goal orientation have shown that individuals with a learning orientation are focused on task mastery and skill development. Such people see knowledge sharing as a means by which to learn and to enhance their personal development. Furthermore, because learning-oriented team members want to challenge themselves persistently when past goals are achieved (Button, Mathieu, \& Zajac, 1996), they are prone to advancing their work goals over time and investing more in knowledge sharing activities, including engaging in work discussions about work related topics (Gray \& Meister, 2004) and soliciting feedback from others (Janssen \& Prins, 2007). With the aim of developing their competence, such team members are, then, likely to seek out information and learn from others (Bunderson \& Sutcliffe, 2003). When both the team member and the leader hold a learning goal orientation, this match can be expected to promote 
knowledge sharing. Indeed, the effect may be multiplicative, team leader and team member spurring each other on through mutual trait activation. In TAT terms, the learning goal cue from the leader will act as a facilitator, magnifying the predisposition of the team member (Tett \& Burnett, 2003). Facilitated by a leader with a learning orientation who evaluates performance over the long term and who sets challenging tasks, learning goal-oriented members will want to achieve a thorough and accurate understanding of the tasks, which will motivate them to search for, interpret, and exchange information systematically (De Dreu, Nijstad, \& van Knippenberg, 2008). Therefore, we posit:

Hypothesis 1a: Leader's learning orientation will positively moderate the relationship between team member's learning orientation and knowledge sharing, in that the positive relationship will be stronger when team leader's learning orientation is higher.

Performance approach goal-oriented leaders emphasize task efficiency and encourage team members to fulfill performance standards, schedules and deadlines (Button et al., 1996). They are personally driven by extrinsic motivational factors. Furthermore, they reward their team members on the basis of demonstrated high levels of ability and performance, making explicit comparisons between members. Suppose a situation where a learning-oriented team member (i.e., someone driven by intrinsic motivational factors) is required to meet the goals set by a leader holding a performance approach goal orientation. While the team member's orientation drives him/her to fully understand the tasks and to explore various options, the team leader is unlikely to allow the member to invest the amount of time and energy that this requires. The team member will feel pressured to demonstrate their ability and meet the short-term performance expectations of their leader (rather than following their predisposition to understand and learn more about the task situation they face) and, therefore, may not be able to engage in knowledge sharing. The trait-relevant situational cue from the team leader is, in TAT terms, a distracter, operating as a negative moderator on the main effect of the team member's learning orientation and knowledge sharing. Therefore, we posit:

Hypothesis 1b: Leader's performance approach orientation will negatively moderate the relationship between team member's learning orientation and knowledge sharing, in that the positive relationship will be weaker when team leader's performance approach is higher.

Individuals who have a performance avoidance goal orientation fear failure and are very concerned with avoiding mistakes and incurring unfavorable evaluations (Elliot \& McGregor, 2001; Porath \& Bateman, 2006). Leaders with a performance avoidance orientation have a tendency to avoid risks, errors, and negative evaluations, and they are likely to perceive information exchange as undesirable and be less inclined to encourage knowledge sharing within the team. A performance avoidance oriented leader will, thus, try to avoid 
demonstrating incompetence and incurring unfavorable outcomes; seek to avoid uncertainties and move quickly from challenging conditions; impose rigid task and evaluation standards that provide little opportunity for team members to exchange ideas and learn from one another; disallow the discussion of errors because such information will reveal that the team is not doing well; and be averse to trial-and-error techniques since experimentation behavior is risky and might damage the image of the team and the leader. The cue from the leader is, then, a constraint, discouraging - even more strongly than the cue of a performance approach leader - team members from sharing knowledge. Therefore, we posit:

Hypothesis 1c: Leader's performance avoidance orientation will negatively moderate the relationship between team member's learning orientation and knowledge sharing, in that the positive relationship will be weaker when team leader's performance orientation is higher.

\section{The Interplay of Performance Approach-Oriented Team Members and Leader's Goal Orientation}

When team members' goal orientation is the performance approach, they are concerned with demonstrating their competence and want to outperform others and prove themselves. They define success primarily in terms of external evaluations. As a result, contextual cues exert a heavy influence on their actions. In that sense, the relationship between performance goal orientation and measures of performance is much more complicated than is the case for either learning orientation or performance avoidance orientation (e.g., Darnon, Harackiewicz, Butera, Mugny, \& Quiamzade, 2007; Gong et al., 2013) and is the likely reason why meta-analyses (e.g., Cellar et al., 2011; Payne et al., 2007) of goal orientation have shown that performance approach orientation is uncorrelated with positive outcomes. Significantly, however, knowledge sharing was not included in the assessment of those outcome variables. In relation to knowledge sharing, it is important to keep in mind that the present study is of persons who are unequal - team members and their leaders, something magnified by the high power distance in China (Hofstede, 2001) - so the impact of cues can be expected to be different than where the individuals are peers (e.g., fellow team members), in which case, they might self-regulate, depending upon their particular goal orientation (Kristof-Brown \& Stevens, 2001). Arguably, the moderating effect of the leader's goal orientation on knowledge sharing will be accentuated, either positively or negatively, as the performance approach-oriented team member makes an instrumental assessment of the situation (Swift et al., 2010).

Team leaders who hold a learning goal orientation attach more importance to long-term success (Elliot \& McGregor, 2001) and often set challenging and demanding tasks and targets (VandeWalle, 1997). The team members' current knowledge base may not be sufficient to deal with these novel and complicated problems. In order to meet the high learning standards of the team leader, 
performance approach-oriented members will respond by learning from each other, and absorbing and assimilating new knowledge. What is more, a leader's learning orientation signals that learning and knowledge sharing comprise an arena in which a team member can demonstrate their competence. In this situation, performance approach-oriented members are likely to believe that they should engage in knowledge sharing to demonstrate their competence and obtain favorable evaluations, by seeking information and experimenting with challenging task approaches. They can prove themselves and may compare favorably to or even outperform their peers by engaging in knowledge sharing behaviors. Thus, when a team leader signals appreciation for learning and sharing (in TAT terms, provides a demand cue), members with a performance approach are motivated to exchange ideas. Thus, we posit:

Hypothesis 2a: Leader's learning orientation will positively moderate the relationship between team member's performance approach orientation and knowledge sharing.

When both the team member and the leader hold a performance approach orientation, there is congruence - or fit - in this respect. They share a common objective of achieving higher performance and, hence, greater rewards than others. This matching orientation, then, produces outcome interdependence, motivating them to pursue positive joint outcomes. We can expect that their similarity is positively related to the quality of their exchange (Phillips \& Bedeian, 1994) and that their relationship lacks tension, providing the opportunity for synergy. In much the way that agreement in performance approach dyads had a positive effect on performance (Darnon et al., 2007), it can be expected that through mutual trait activation there will be a shared goal of gaining favorable external evaluation which draws team members together and inspires them to share task-related knowledge (Chen \& Kanfer, 2006). The overall effect will be greater knowledge sharing in the interests of achieving targets and goals. This effect will be accentuated in the context of an organization or organizational sub-unit where organizational performance is very much a function of knowledge and knowledge sharing (such as design teams comprising members from diverse professional backgrounds, as in this study). Since a shared vision and collective goal is likely to facilitate the sharing of resources - including, but not limited to, knowledge and ideas - the overall impact, through the effect of a facilitator cue, can be expected to be highly positive. Thus, we posit:

Hypothesis 2b: Leader's performance approach orientation will positively moderate the relationship between team member's performance approach orientation and knowledge sharing.

Since performance approach-oriented team members are sensitive to external cues in order to maximize extrinsic rewards, they are more responsive to contextual cues, especially those coming from team leaders, including the leader's goal 
orientation. Performance avoidance team leaders will be intent on avoiding uncertainties and challenging, risk-bearing conditions (VandeWalle, 1997). They are unlikely to encourage learning because of the inherent risks involved. In circumstances, then, where the leader is averse to reflective problem solving, performance approach-oriented team members are less likely to be motivated to share knowledge since they will have formed the view that they are unlikely to be rewarded for investing time and energy in learning and knowledge sharing activities. Given the leader's control of the evaluation and reward system, the disincentives for such behavior can be expected to create a strong effect. In TAT terms, there will be a strong constraint cue operating. Thus, we posit:

Hypothesis 2c: Leader's performance avoidance orientation will negatively moderate the relationship between team member's performance approach orientation and knowledge sharing.

\section{The Interplay of Performance Avoidance-Oriented Team Members and Leader's Goal Orientation}

Team members whose predominant goal orientation is performance avoidance will have a tendency to avoid making mistakes or risking failure (VandeWalle, 1997). Since knowledge sharing and learning new skills imply unpredictability and are likely connected to setbacks, flaws, and problems, performance avoidance-oriented members will be inclined to avoid knowledge sharing unless contextual factors reduce their inherent psychological risks.

As learning oriented leaders emphasize long-term results, they can tolerate short-term mistakes and often use trial-and-error techniques to encourage learning. The demands cue from such leaders signals to performance avoidance-oriented members that they are less likely to be criticized for errors or mistakes, and that learning and knowledge sharing are appropriate, supported, encouraged and rewarded. Besides making demands clear and explicit, learning oriented leaders are likely to create a work environment and structure events that deliberately encourage team members to increase their knowledge sharing; in other words, such leaders may invoke releasers as another means of achieving the outcomes they want. As a result, the psychological risks associated with learning are reduced (Siemsen, Roth, Balasubramanian, \& Anand, 2009). Such risk reduction is likely to lower the threshold for engagement in knowledge sharing by creating a tolerant atmosphere and encouraging team members to express and explore various perspectives. Thus, we posit:

Hypothesis 3a: Leader's learning orientation will positively moderate the relationship between team member's performance avoidance orientation and knowledge sharing, in that the negative relationship will be weaker when team leader's learning orientation is higher.

Leaders with a predominant performance approach orientation can be expected to do little to encourage or facilitate learning and knowledge sharing,

(C) 2018 The International Association for Chinese Management Research 
other than when it might promote the achievement of short-term goals (Button et al., 1996). For a team member whose orientation is performance avoidance, the situation they face is therefore likely to be confusing and their uncertainties and anxieties surrounding their fundamental risk aversion increased by being unclear about what is expected of them in relation to knowledge sharing. In that sense, the cues from a performance approach-oriented leader in relation to a performance avoidance team member are distracters and are likely to have a negatively moderating effect. Thus, we posit:

Hypothesis 3b: Leader's performance approach orientation will negatively moderate the relationship between team member's performance avoidance orientation and knowledge sharing, in that the negative relationship will be stronger when the leader's performance approach is higher.

When both the leader and the team member have a performance avoidance orientation, there will be agreement about the need to avoid risky situations that might lead to errors, failure, and criticism, as well as a reluctance to engage in the feedback that knowledge sharing implies (Payne et al., 2007). In this case, it is likely that knowledge sharing activities will be restrained. The leader's goal orientation will reinforce the predispositions of the member, acting as a facilitator cue. In other words, there will be negatively focused mutual trait activation and reinforcement. Thus, we posit:

Hypothesis 3c: Leader's performance avoidance orientation will negatively moderate the relationship between team member's performance avoidance orientation and knowledge sharing, in that the negative relationship will be stronger when team leader's performance avoidance orientation is higher.

\section{METHODS}

\section{Sample and Procedures}

The research setting for this study was two Beijing-based companies that focus on design, engineering, and construction. These companies provide technical services in the area of municipal engineering, aviation planning and construction. The majority of employees are engineers, holding bachelor's or master's degrees. Different from other design and research institutions, these two companies offer technical support covering the entire life cycle of engineering projects and provide interdisciplinary scientific consultancy to their clients. To deliver integrated solutions, the firms organize temporary project teams composed of members drawn from relevant areas of expertise (e.g., architecture, structure, plumbing, equipment, electrical, material engineering, accounting, etc.). Therefore, knowledge sharing among team members, and with relevant external members, is of critical importance to project success. Project leaders play a pivotal role in managing and facilitating knowledge flows in these projects due to the inherent complexity of required knowledge, the high degree of heterogeneity, and often a short history of project teams. 
We first piloted the questionnaire in March 2013 among six construction project teams in one of the two subject companies. The teams in the pilot study ranged in size from 6 to 15 members, and their tasks included subway expansion, river training and road construction. With four of the teams, the survey was administered by one of the researchers face to face in order to assess the length of time required to complete the questionnaire, gauge the reactions of respondents, and uncover any errors in the survey instrument. The other two teams were surveyed via email subsequently. In the pilot study, we also consulted the company's senior managers, various team leaders and experts in the domain of civil engineering about the survey instrument.

In December 2013, the verified questionnaire was distributed to 160 team members and 25 team leaders in the two companies, whose projects included airport construction, irrigation works, subway expansion and road building and design. The teams ranged in size from 5 to 15 members. All members in the team were invited to participate in the survey. Supported by the companies' senior management we verified that all participating teams met the requirement of knowledge sharing for the purpose of this study.

In order to capture knowledge sharing more precisely and to test the temporal linkages among multilevel variables, we collected the data in two phases. Specifically, during phase one, we conducted a survey to measure demographic variables, control variables and individual's goal orientation. Twenty-five team leaders and 160 team members completed the survey during this phase. Four months later, during phase two, we conducted a survey to measure knowledge sharing among team members and team leaders. Twenty-five team leaders and 156 team members completed the survey. So, the total sample size of this study was 181 (25 team leaders and 156 team members). The response rates to the surveys were almost $100 \%$. The very high response rates are a reflection of the nature of organizations in collectivistic, high power distance cultures, where the endorsement of senior management for the study ensures that most people will respond (Everett \& Stening, 1980).

The average team size was 7.2 employees. Of the team members, $86.7 \%$ were male, $62.9 \%$ had undergraduate degrees, and $5.6 \%$ had postgraduate degrees. Average age was 36.5 years, and average team tenure was 25.1 months. Of the team leaders, $92 \%$ were male, $70 \%$ had undergraduate degrees and $11.4 \%$ had postgraduate degrees. Average age was 39.6 years, and average team tenure was 35.1 months.

\section{Measures}

Goal orientation. The goal orientations of both team leaders and members were measured using VandeWalle's (1997) seven-point scales ranging from 1, 'not at all', to 7 , 'to a large extent'. An example of the five-item learning orientation questions is, 'I'm willing to select a challenging work assignment that I can learn a lot from'. An

(C) 2018 The International Association for Chinese Management Research 
example of the four-item performance approach orientation questions is, 'I'm concerned with showing that I can perform better than my co-workers'. An example of the four-item performance avoidance orientation questions is, 'I would avoid taking on a new task if there was a chance that I would appear rather incompetent to others'. All measures displayed satisfactory reliability $(\alpha>0.70)$.

To examine the factor structure of the goal orientation items, we conducted confirmatory factor analyses among 181 respondents $(25$ team leaders and 156 team members). The three-factor model provided a good fit to the data $\left(\chi^{2}=\right.$ 124.77, $\mathrm{df}=61, \mathrm{p}<0.01$; root-mean-square error of approximation [RMSEA] $=0.07$, comparative fit index $[\mathrm{CFT}]=0.93$, and a Tucker-Lewis index $[\mathrm{TLC}]=$ 0.91). The three-factor model fit the data significantly better than did the twofactor model $\left(\chi^{2}=245.10, \mathrm{df}=63, \mathrm{p}<0.01 ; \mathrm{RMSEA}=0.13, \mathrm{CFI}=0.79\right.$, and $\mathrm{TLI}=0.74)$ and the one-factor model $\left(\chi^{2}=497.9, \mathrm{df}=64, \mathrm{p}<0.01\right.$; RMSEA $=$ $0.19, \mathrm{CFI}=0.50$, and $\mathrm{TLI}=0.39)$, supporting the discriminant validity of goal orientation scales.

Knowledge sharing. We measured knowledge sharing by assessing an individual's intention to, and behavior of, sharing task-related ideas, exchanging task-relevant information, and providing suggestions to members within the same project team and external members of a task-adviser network (including members of other project teams, members of other units in the same company). The reason we included external members is that the sources from which team members seek knowledge and advice become more diverse when their tasks get more complex and solving task-related problems requires more multi-disciplinary knowledge. Furthermore, our research setting is project teams composed of members drawn from diverse areas of expertise, on a temporary basis. In such setting, knowledge sharing often extends beyond the boundary of the immediate project team. According to our conversations with the respondents, team members often discuss workrelated tasks with the members of previous teams they worked, or colleagues with the similar domain of expertise but located in other units. Thus, knowledge sharing does not constrain within the team, and knowledge sharing with external members is an important complement to within-team knowledge sharing.

To address this challenge, we adopted the advice network approach (Hansen, 1999; Reagans \& McEvily, 2003), which has been commonly used to measure knowledge seeking and receiving behaviors of members within a network. For within-team knowledge sharing, we provided each participant with a list of people within the team, in order to improve the accuracy and reliability of the survey (Labianca, Brass, \& Gray, 1998; Marsden, 1990). To assess an individual's intention to share knowledge with his/her team members, we asked respondents, 'In the past years, with whom do you communicate, ask for help, or seek advice about work-related topics', an item that was modified from the work of Brass (1985) and Burkhardt (1994). This is known as the roster method. The measure is intended to assess problem-oriented communication involving two-way 
knowledge sharing. For beyond team knowledge sharing, we use the name generator method (Marsden, 1990). ${ }^{[1]}$ In this way the respondents could nominate as many contacts as they regarded appropriate, from whom they obtained knowledge (i.e., beyond normal working teams). This free choice approach has been proved to be effective in reducing measurement errors and enhancing the reliability (Marsden, 1990), and regarded as a good complementary method to a fixed-choice advice network design (Perry-Smith, 2006). In sum, the knowledge sharing measure in this study is the aggregate result of knowledge sharing intention and behavior within the team (internal sources) and beyond the team (external sources).

Control variables. We included several control variables at both the individual and team levels. At the individual level we controlled for position status (measured as a categorical variable position: 1='employee'; 2='bottom manager'; 3='middle manager'; 4='senior manager'), and team tenure, which is measured as the time working with present team leaders (George \& Jing, 2007). One critical factor influencing the relative ease of knowledge sharing is the receiver's and sender's expertise domain and knowledge breadth (Reagans \& McEvily, 2003; Von Hippel, 1994; Zander \& Kogut, 1995), it being easier for an individual to accumulate knowledge in shared domains between the receiver and the sender and in areas where the receiver has a broad knowledge base. Therefore, to measure expertise domain, respondents were asked to indicate whether they had previous work experience in each of the seven functional areas: design, construction, equipment management, procurement, R\&D, finance or accounting and general management. Respondents were also asked to report other functional areas that were not listed but they had previous experience in. To measure knowledge breadth, respondents were asked to indicate whether they had deep knowledge in each of the seven professional disciplines: architecture, civil engineering, water supply and drainage, electrical engineering, geotechnical engineering and energy engineering, and automatic control. Respondents were also asked to report other professions that were not listed but they had knowledge in that discipline. We measured expertise domain and knowledge breadth by counting the number of fields where respondents had previous experience or knowledge. At the team level, we controlled for team size. In addition, since it has been noted that transformational leadership is linked to a follower's motivation to perform beyond standard expectations and may have a positive influence on knowledge management (e.g., Bryant, 2003; Huang, Davison, Liu, \& Gu, 2008), we controlled for transformational leadership to partial out any potential leadership style effects on knowledge sharing. We measured transformational leadership using the rater form of the Multifactor Leadership Questionnaire MLQ Form 5X (Avolio \& Bass, 1995). Finally, we controlled for team task interdependence, as this might influence the knowledge sharing process (Janssen \& Van Yperen, 2004). We measured this variable using a single item from Shin and Zhou (2007: 1714): 'The work I usually do is a group project rather than an individual project' ( $1=$ 'strongly disagree', $7=$ 'strongly agree').

(C) 2018 The International Association for Chinese Management Research 


\section{Data Analysis}

In this research, team members' goal orientation and knowledge sharing are individual-level variables, however, we treat team leaders' goal orientation as a teamlevel variable. This is because team leaders play a multi-functional role which has direct consequences on team activities and performance. Individual level variables are embedded in team-level (higher level) variables (Liao \& Chuang, 2004). For this reason, we adopted the hierarchical linear modeling (HLM) to test our hypotheses across levels (i.e., team members' goal orientation and knowledge sharing at level 1 and team leaders' goal orientation at level 2, as shown in Figure 1) (Raudenbush, Bryk, Cheong, \& Congdon, 2004), as this analytic technique provides a more comprehensive test of a multilevel data structure.

We hypothesize that the leader's goal orientation activates the relationship between the team member's goal orientation and knowledge sharing. To minimize any potential problems of multicollinearity and to better interpret the results, we centered the predictor variables before calculating the cross-product terms (Aiken \& West, 1991). Except for position, manager tenure, expertise domain, and knowledge breadth variables, the individual-level predictors are all grand-mean centered. For the team-level variables, we also grand-mean centered the leader's three goal orientation variables.

\section{RESULTS}

We tested within-team agreement for transformational leadership and task interdependence by computing within-group inter-rater agreement $\left(\gamma_{w g}\right)$, using a normal distribution (James, Demaree, \& Wolf, 1984). This test yielded mean values of 0.91 and 0.85 , respectively, indicating adequate within-team agreement. The ICC1 and ICC2 estimates for transformational leadership were 0.19 and 0.61 , respectively. The ICG1 and ICC2 estimates for task interdependence were 0.17 and 0.67, respectively. Overall, these statistics met or exceeded the levels found in prior research dealing with aggregation (Gong et al., 2013; Hirst et al., 2009). Thus, we aggregated the responses for transformational leadership and task interdependence to the team level. Descriptive statistics, reliability estimates, and correlations are shown in Table 1.

Table 2 shows the baseline regressions using hierarchical linear modeling. First, we used a null model to test the significance of the between-team variance in knowledge sharing. Then, we entered both the individual-level and team-level control variables in Model 1. Members' goal orientation indicators were introduced in Model 2; and leaders' goal orientation predictors were added in Model 3.

Table 3 presents the cross-level moderation effects using hierarchical linear modeling. Besides independent variables and control variables, the interaction terms of the leader's three goal orientation indicators with member's learning goal orientation were introduced in Model 1. Then, the activating role of the 
Table 1. Means, standard deviations, and correlations

\begin{tabular}{|c|c|c|c|c|c|c|c|c|c|}
\hline Variable & Mean & s.d. & 1 & 2 & 3 & 4 & 5 & 6 & 7 \\
\hline \multicolumn{10}{|l|}{ Individual level $^{a}$} \\
\hline 1. Position & 3.64 & 0.51 & & & & & & & \\
\hline 2. Team tenure & 27.83 & 27.12 & 0.20 & & & & & & \\
\hline 3. Expertise domain & 1.69 & 1.11 & -0.20 & -0.08 & & & & & \\
\hline 4. Knowledge breadth & 1.64 & 0.91 & -0.15 & $-0.24 *$ & $0.43^{*}$ & & & & \\
\hline 5. Learning goal & 6.01 & 0.87 & -0.15 & -0.14 & 0.06 & 0.12 & $(0.81)$ & & \\
\hline 6. Performance approach goal & 5.17 & 0.90 & -0.17 & 0.10 & 0.04 & 0.018 & $0.30^{*}$ & $(0.76)$ & \\
\hline 7. Performance avoidance goal & 3.24 & 1.29 & -0.08 & 0.08 & -0.03 & -0.04 & $-0.22^{*}$ & 0.20 & $(0.85)$ \\
\hline 8. Knowledge sharing & 2.50 & 0.75 & -0.12 & 0.016 & 0.07 & 0.16 & $0.26^{*}$ & 0.10 & $-0.23^{*}$ \\
\hline \multicolumn{10}{|l|}{ Team level $^{b}$} \\
\hline 1. Team size & 7.20 & 3.01 & & & & & & & \\
\hline 2. Task interdependence & 2.71 & 0.85 & 0.17 & & & & & & \\
\hline 3. Transformational leadership & 2.81 & 0.51 & 0.01 & -0.22 & $(0.92)$ & & & & \\
\hline
\end{tabular}

Notes: ${ }^{\mathrm{a}} \mathrm{n}=156 ;{ }^{\mathrm{b}} \mathrm{n}=25$.

$* p<0.01$. 
Table 2. Hierarchical linear modeling of baseline predictors of knowledge sharing

\begin{tabular}{|c|c|c|c|c|c|c|}
\hline \multirow[b]{2}{*}{ Variable } & \multicolumn{2}{|c|}{ Model 1} & \multicolumn{2}{|c|}{ Model 2} & \multicolumn{2}{|c|}{ Model 3} \\
\hline & Estimate & $S E$ & Estimate & $S E$ & Estimate & $S E$ \\
\hline Intercept & $2.83^{* * *}$ & 0.71 & $2.79 * * *$ & 0.71 & $2.56^{* * *}$ & 0.68 \\
\hline \multicolumn{7}{|l|}{ Level 1 variables } \\
\hline Position & 0.14 & 0.10 & 0.13 & 0.09 & 0.13 & 0.09 \\
\hline Team tenure & 0.06 & 0.04 & 0.07 & 0.05 & 0.07 & 0.05 \\
\hline Expertise domain & 0.03 & 0.03 & 0.03 & 0.03 & 0.03 & 0.03 \\
\hline Knowledge breadth & $0.32 * *$ & 0.15 & $0.13^{*}$ & 0.07 & $0.15 * *$ & 0.07 \\
\hline Learning goal & & & $0.41 * * *$ & 0.12 & $0.41 * * *$ & 0.11 \\
\hline Performance approach goal & & & 0.12 & 0.07 & 0.11 & 0.07 \\
\hline Performance avoidance goal & & & $-0.19 * *$ & 0.08 & $-0.19 * *$ & 0.08 \\
\hline \multicolumn{7}{|l|}{ Level 2 variables } \\
\hline Team size & $-0.09 *$ & 0.05 & $-0.09 *$ & 0.05 & -0.09 & 0.06 \\
\hline Task interdependence & $0.26 * *$ & 0.12 & $0.26 * *$ & 0.12 & $0.26^{* *}$ & 0.12 \\
\hline Transformational leadership & $0.39 * * *$ & 0.12 & $0.39 * * *$ & 0.12 & $0.37 * * *$ & 0.11 \\
\hline Leader's learning goal & & & & & $0.27 * *$ & 0.13 \\
\hline Leader's performance approach goal & & & & & 0.04 & 0.03 \\
\hline Leader's performance avoidance goal & & & & & -0.09 & 0.06 \\
\hline Deviance & \multicolumn{2}{|c|}{319.4} & \multicolumn{2}{|c|}{313.6} & \multicolumn{2}{|c|}{309.5} \\
\hline Total $R^{2 b}$ & \multicolumn{2}{|c|}{0.12} & \multicolumn{2}{|c|}{0.15} & \multicolumn{2}{|c|}{0.17} \\
\hline
\end{tabular}

Notes: ${ }^{\mathrm{a}} \mathrm{n}=156$ team members and 25 team leaders. ${ }^{\mathrm{b}}$ Indicates $R_{\text {within-group }}^{2} \times(1-I C C 1)+R_{\text {between-groups }}^{2} \times I C C 1$. $* p<0.10 ; * * p<0.05 ; * * * p<0.01$; Two-tailed test.

leader's three goal orientation indicators on member's performance approach goal orientation was tested in Model 2. Finally, the interactions of leaders' three goal orientation indicators with members' performance avoidance goal orientation were added in Model 3.

The null model indicated that $39 \operatorname{percent}\left(\tau_{00}=0.61 \mathrm{p}<0.001, \mathrm{ICC} 1=0.39\right)$ of the variance can be explained by team level variables. For the cross-level interaction hypotheses, we tested whether the slopes of the member goal orientations and knowledge sharing varied among teams. The analysis showed significant variance in the individual level slopes of members' goal orientations and knowledge sharing: learning goal orientation $\left(\mathrm{U} 1\right.$ variance $=0.49, \chi^{2}[24]=172.31, \mathrm{p}<$ 0.01 , performance approach goal orientation $\left(\mathrm{U} 1\right.$ variance $=0.54, \chi^{2}[24]=$ 194.62, $\mathrm{p}<0.01$ ), and performance avoidance goal orientation $(\mathrm{U} 1$ variance $=$ $\left.0.43, \chi^{2}[24]=166.53, \mathrm{p}<0.01\right)$.

The results for the baseline relationship of goal orientation and knowledge sharing confirm prior studies. Team member's learning goal orientation is significantly positively related to knowledge sharing $(\gamma=0.41, \mathrm{p}<0.01)$; team member's performance approach goal orientation is not significantly related to knowledge sharing $(\gamma=0.12$, n.s.); and team member's avoidance orientation is significantly negatively related to knowledge sharing $(\gamma=-0.19, \mathrm{p}<0.05)$. As for team 
Table 3. Hierarchical linear modeling of cross-level interactions

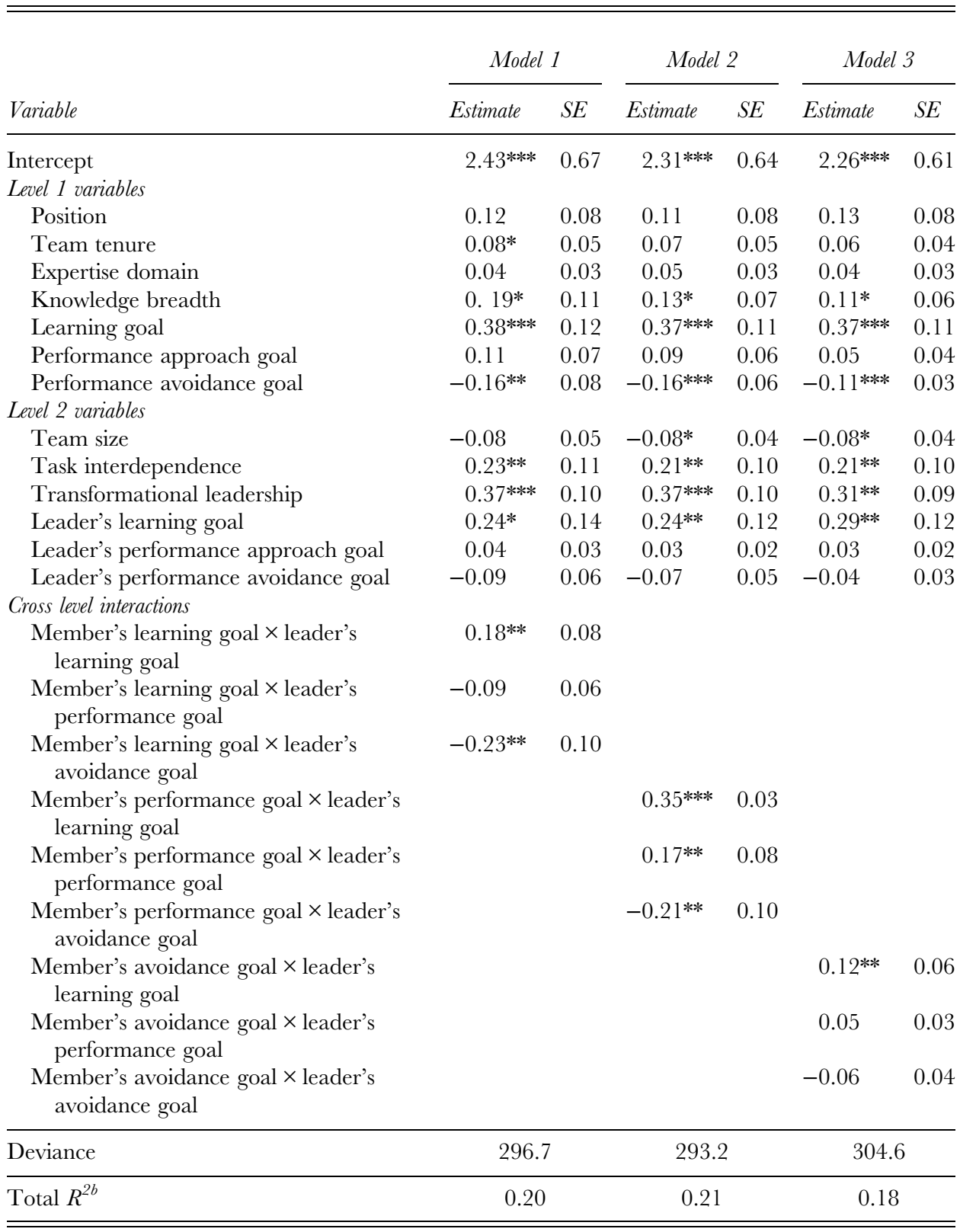

Notes: ${ }^{\mathrm{a}} \mathrm{n}=156$ team members and 25 team leaders. ${ }^{\mathrm{b}}$ Indicates $R_{\text {within-group }}^{2} \times(1-I C C 1)+R_{\text {between-groups }}^{2} \times I C C 1$. $* p<0.10 ; * * p<0.05 ; * * * p<0.01$; Two-tailed test.

leader's goal orientations, only team leader's learning goal orientation demonstrates a significant (and positive effect) on knowledge sharing $(\gamma=0.27, \mathrm{p}<0.05)$. Hypothesis la stated that a leader's learning goal orientation positively moderates the relationship between a team member's learning goal orientation and knowledge sharing. The results in Model 1 of Table 3 show that the interaction 


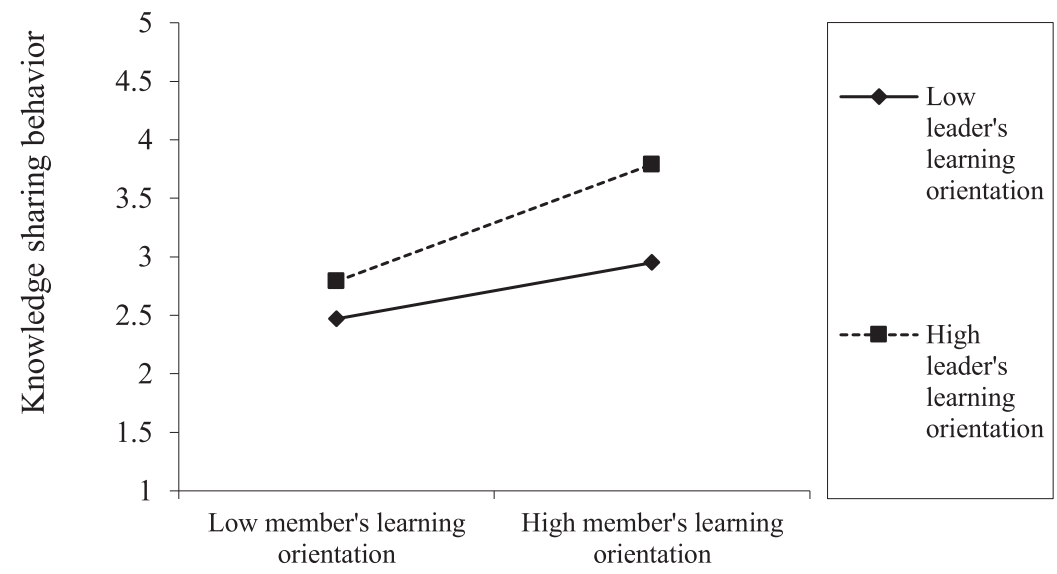

a

Figure 2a. Interaction between leader's learning orientation and member's learning orientation predicting individual knowledge sharing

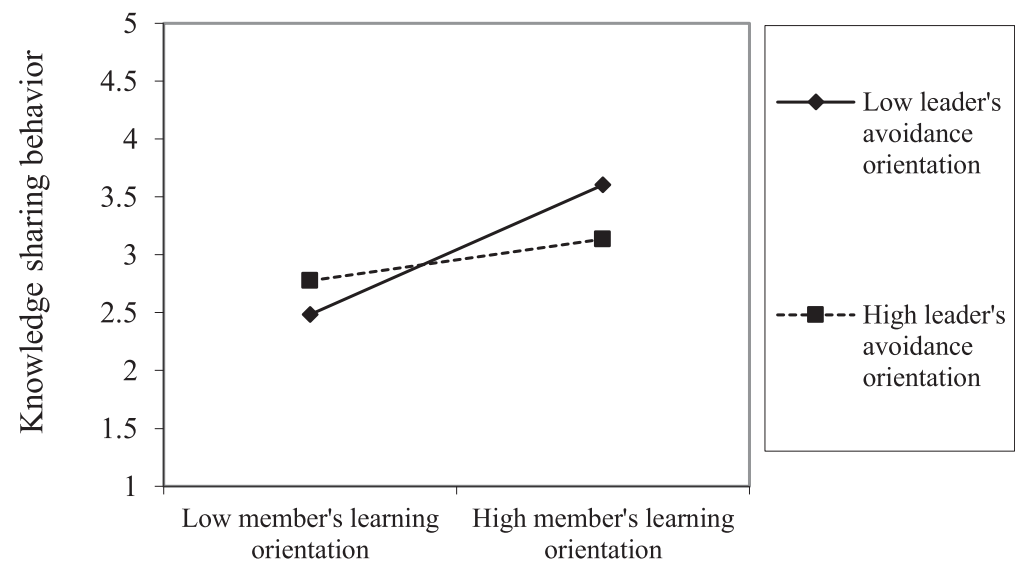

b

Figure 2b. Interaction between leader's avoidance orientation and member's learning orientation predicting individual knowledge sharing

between leader's learning goal orientation and member's learning goal orientation is significant $(\gamma=0.18, \mathrm{p}<0.05)$, supporting H1a. This effect is plotted in Figure 2a. The simple slope in the condition of high leader's learning goal orientation (one SD above the mean) is significant $\left(\gamma_{h i g h}=0.58, \mathrm{SE}=0.12, \mathrm{t}=4.83, \mathrm{p}<\right.$ $0.00)$, while the simple slope in the condition of low leader's learning goal orientation is not significant $\left(\gamma_{\text {low }}=0.18, \mathrm{SE}=0.11, \mathrm{t}=1.63, \mathrm{p}>0.10\right)$. These results suggest that when leader's learning goal orientation is high, it enhances the positive relationship between member's learning goal orientation and knowledge sharing, but when leader's learning goal orientation is low, there is no relationship between member's learning goal orientation and knowledge sharing. These results provide further support for Hypothesis la. 
Hypothesis $1 \mathrm{~b}$ predicted that a leader's performance approach goal orientation negatively moderates the relationship between a team member's learning goal orientation and knowledge sharing. As indicated in Table 3, while the effect was negative, it was not significant $(\gamma=-0.09$, n.s.). The simple slope in the condition of high leader's performance approach goal orientation (one SD above the mean) is not significant $\left(\gamma_{\text {high }}=0.32, \mathrm{SE}=0.21, \mathrm{t}=1.52, \mathrm{p}>0.10\right)$, and the simple slope in the condition of low leader's performance approach goal orientation is not significant $\left(\gamma_{\text {low }}=0.42, \mathrm{SE}=0.26, \mathrm{t}=1.62, \mathrm{p}>0.10\right)$. Hypothesis $1 \mathrm{~b}$ is, therefore, not supported.

Hypothesis 1c stated that team leader's performance avoidance orientation negatively moderates the relationship between a team member's learning goal orientation and knowledge sharing. The results in Model 1 of Table 3 show that the interaction between leader's performance avoidance orientation and member's learning goal orientation is significant $(\gamma=-0.23, \mathrm{p}<0.05)$, supporting H1c. This effect is plotted in Figure 2b. The simple slope in the condition of high leader's performance avoidance orientation (one SD above the mean) is not significant $\left(\gamma_{\text {high }}=0.08, \mathrm{SE}=0.06, \mathrm{t}=1.33, \mathrm{p}>0.10\right)$, while the simple slope in the condition of low leader's performance avoidance orientation is significant $\left(\gamma_{\text {low }}=0.68\right.$, $\mathrm{SE}=0.09, \mathrm{t}=7.56, \mathrm{p}<0.00)$. These results suggest that when leader's performance avoidance orientation is high, there is no relationship between member's learning goal orientation and knowledge sharing, but when leader's performance avoidance orientation is low, it enhances the positive relationship between member's learning goal orientation and knowledge sharing. These results provide support for Hypothesis 1c.

Hypothesis 2a stated that a leader's learning goal orientation positively moderates the relationship between a team member's performance approach goal orientation and knowledge sharing. The results in Model 2 of Table 3 show that the interaction between leader's learning goal orientation and member's performance approach goal is significantly positive $(\gamma=0.35, \mathrm{p}<0.01)$, supporting H2a. This effect is plotted in Figure 3a. The simple slope in the condition of high leader's learning goal orientation (one SD above the mean) is significantly positive $\left(\gamma_{\text {high }}=0.41, \mathrm{SE}=0.09, \mathrm{t}=4.56, \mathrm{p}<0.00\right)$, while the simple slope in the condition of low leader's learning goal orientation is significantly negative $\left(\gamma_{\text {low }}=-0.23, \mathrm{SE}=\right.$ $0.09, \mathrm{t}=1.63, \mathrm{p}<0.01)$. These results suggest that when leader's learning goal orientation is high, member's performance approach goal orientation is positively related to knowledge sharing, but when leader's learning goal orientation is low, member's performance approach goal orientation is negatively related to knowledge sharing. These results provide support for Hypothesis 2a.

Hypothesis 2b predicted that a leader's performance approach goal orientation positively moderates the relationship between a team member's performance approach goal orientation and knowledge sharing. The results in Model 2 of Table 3 show that the interaction between leader's performance approach goal orientation and member's performance approach goal is significantly positive 



a

Figure 3a. Interaction between leader's learning orientation and member's approach orientation predicting individual knowledge Sharing

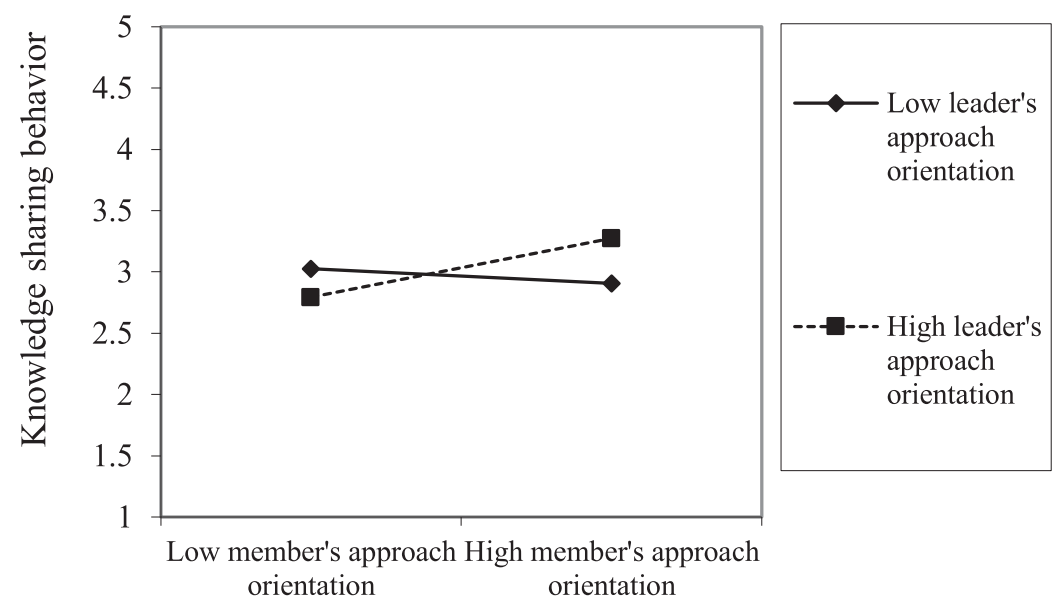

b

Figure 3b. Interaction between leader's approach orientation and member's approach orientation predicting individual knowledge sharing

$(\gamma=0.17, \mathrm{p}<0.01)$, supporting H2b. This effect is plotted in Figure $3 \mathrm{~b}$. The simple slope in the condition of high leader's performance approach goal orientation (one $\mathrm{SD}$ above the mean $)$ is significant $\left(\gamma_{\text {high }}=0.24, \mathrm{SE}=0.11, \mathrm{t}=2.18, \mathrm{p}<0.05\right)$, while the simple slope in the condition of low leader's performance approach goal orientation is not significant $\left(\gamma_{\text {low }}=-0.06, \mathrm{SE}=0.09, \mathrm{t}=0.67, \mathrm{p}>0.10\right)$. These results suggest that when leader's performance approach goal orientation is high, it enhances the positive relationship between member's performance approach goal orientation and knowledge sharing, but when leader's performance approach goal orientation is low, there is no relationship between member's performance approach goal orientation and knowledge sharing. These results provide support for Hypothesis $2 b$. 


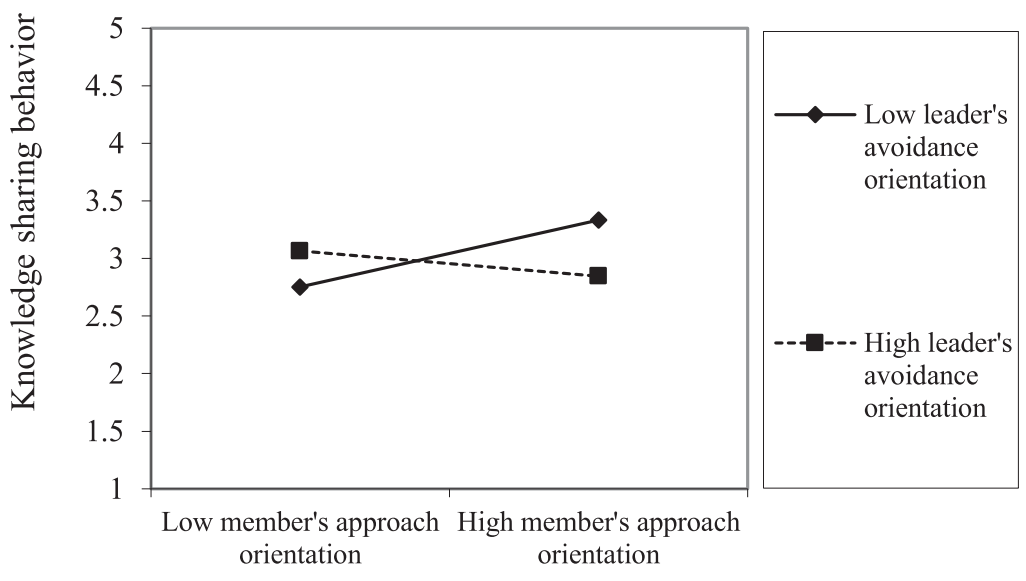

$\mathrm{c}$

Figure 3c. Interaction between leader's avoidance orientation and member's approach orientation predicting individual knowledge sharing

Consistent with Hypothesis 2c, a team leader's performance avoidance orientation negatively moderates a team member's performance approach orientation and knowledge sharing $(\gamma=-0.21, \mathrm{p}<0.05)$. This effect is plotted in Figure 3c. The simple slope in the condition of high leader's performance avoidance orientation (one SD above the mean) is significantly negative $\left(\gamma_{\text {high }}=-0.18, \mathrm{SE}=0.09\right.$, $\mathrm{t}=2.03, \mathrm{p}<0.05$ ), while the simple slope in the condition of low leader's performance avoidance orientation is significantly positive $\left(\gamma_{\text {low }}=0.36, \mathrm{SE}=0.09, \mathrm{t}=4.02\right.$, $\mathrm{p}<0.01)$. These results suggest that when leader's performance avoidance orientation is high, member's performance approach goal orientation significantly negatively impacts knowledge sharing, but when leader's performance avoidance orientation is low, member's performance approach goal orientation is significantly positive in relation to knowledge sharing. These results provide support for Hypothesis 2c.

Hypothesis 3 a predicted that a team leader's learning goal orientation would positively moderate the relationship between a team member's performance avoidance orientation and knowledge sharing. The results in Model 3 of Table 3 show that the interaction between leader's learning goal orientation and member's performance avoidance orientation is significant $(\gamma=0.12, \mathrm{p}<0.05)$, supporting H3a. This effect is plotted in Figure 4. The simple slope in the condition of high leader's learning goal orientation (one SD above the mean) is not significant $\left(\gamma_{\text {high }}\right.$ $=0.04, \mathrm{SE}=0.06, \mathrm{t}=0.67, \mathrm{p}>0.10)$, while the simple slope in the condition of low leader's learning goal orientation is significant $\left(\gamma_{\text {low }}=0.36, \mathrm{SE}=0.15\right.$, $\mathrm{t}=2.42, \mathrm{p}<0.05)$. These results suggest that when leader's learning goal orientation is high, there is no relationship between member's performance avoidance orientation and knowledge sharing, but when leader's learning goal orientation is low, it relieves the negative relationship between member's performance avoidance orientation and knowledge sharing. These results provide support for Hypothesis 3a. 


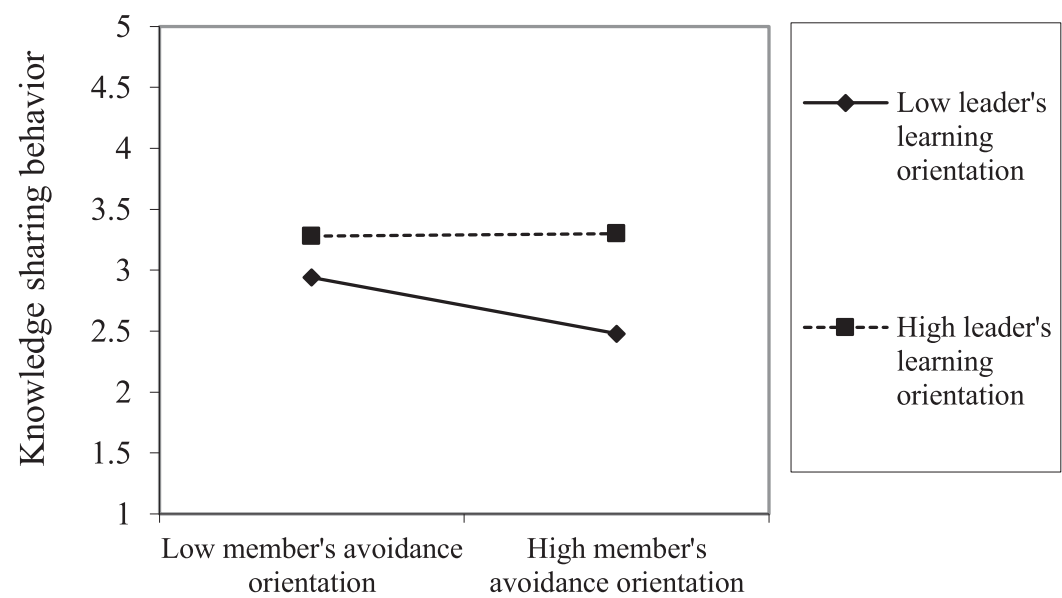

Figure 4. Interaction between leader's learning orientation and member's avoidance orientation predicting individual knowledge sharing

Hypothesis $3 \mathrm{~b}$ predicted that a team leader's performance approach orientation would negatively moderate the relationship between a team member's performance avoidance orientation and knowledge sharing. The prediction was not supported and the relationship was, in fact, weakly positive and not significant $(\gamma=0.05$, n.s. $)$. Where both the leader and the member had a performance avoidance goal orientation, Hypothesis 3c predicted that a leader's performance avoidance orientation would negatively moderate the relationship between a team member's performance avoidance orientation and knowledge sharing. Though the effect was negative, it was not statistically significant $(\gamma=-0.06$, n.s.).

It should be noted that in Tables 2 and 3 we report the estimate and standard error for each variable. To verify effect sizes of the regression models, we report total $R^{2}$ and deviance as explained variance in the HLM models. The explained variance in our HLM models is comparable to other studies using the same techniques (Gong et al., 2013; Hirst et al., 2009).

\section{DISGUSSION}

The results of the interplay between the nine possible combinations of leadermember goal orientations substantiated all but one of our nine hypotheses directionally. In six of the nine interplays: positively in every case where the leader had a learning goal orientation; positively where the leader and member both had a performance approach orientation; and negatively where the leader's orientation was performance avoidance and the team member had either a learning- or a performance-approach orientation. Overall, the results indicated not only that different leader-member goal orientation combinations resulted in (with one exception) predictable outcomes, but also that they followed distinctive patterns. Knowledge sharing is enhanced when: there is congruence in the learning or performance approach orientations of the leader and members; and when the leader 
has a learning orientation, regardless of the member's orientation. On the other hand, knowledge sharing is not engaged in: when the leader has a performanceavoidance orientation; and where the leader has a performance-approach orientation but the member has a learning orientation.

In relation to the lack of support for three of the hypotheses, two principal explanations seem feasible. First, in relation to Hypotheses $3 \mathrm{~b}$ and 3c, where the member's performance-avoidance orientation was not negatively moderated by either a performance-approach orientation or a performance-avoidance orientation on the part of the leader, it might reasonably be argued that there is a 'saturation' effect such that if the member is already not inclined to share knowledge, the leader's desire for them not to do so will not increase that propensity. Second, in relation to Hypothesis $1 \mathrm{~b}$, the impact of culture might have been exerted in that even if the leader has, through their performance approach orientation, a propensity not to share knowledge, if there are strong in-group norms of reciprocity (typical of Chinese behavior) (Shang, Fu, \& Chong, 2012) then a team member with a learning orientation might be encouraged to persist with knowledge sharing.

\section{Theoretical Implications}

Our results have shown that, irrespective of their own goal orientations, leaders have a clear and consistent impact on performance approach members; learning goal-oriented leaders consistently have a positive impact; and performance avoidance leaders consistently have a negative impact. Looked at from the perspective of team member's behavior, two things are noteworthy. First, performance approachoriented members are highly responsive to the goal orientations of their leaders. Second, in contrast, except where the leader has a learning orientation, performance avoidance members are not responsive to the goal orientations of their leaders, confirming previous findings (e.g., Darnon et al., 2007; Elliot \& McGregor, 2001) in the leader-member context.

Managers in organizations play a central role, not only (at senior levels) in creating an overall climate conducive to successful knowledge sharing (Argote, 2013), including by providing incentives (Bartol \& Srivastava, 2002), but (at lower levels) by sending an array of signals to their team members which encourage, or discourage, knowledge sharing. It is not enough, we argued, merely to examine, as previous studies have, the direct relationship between an individual team member's goal orientation and their willingness or otherwise to share knowledge. While it is also acknowledged that team goal orientations are important (Gong et al., 2013), neither is this sufficient to explain knowledge sharing. Our study has enriched the literature on goal orientation and knowledge sharing by underlining the central importance of leaders' role in moderating the relationship between individual team members' goal orientation and their knowledge sharing. Using the lens of various TAT cues (demands, distracters, constraints, releasers and facilitators) we have explained how leaders play such a role. Cumulatively, our findings add to the

(C) 2018 The International Association for Chinese Management Research 
understanding of the conditions under which knowledge sharing will or will not occur in relation to leaders' goal orientation.

\section{Practical Implications}

Knowledge sharing has practical implications in three areas: recruitment and selection (of both team leaders and team members); development of team members; and the shaping of organizational culture in a way that supports the interactions of team leaders and members, as well as relations between team members, to enhance knowledge sharing and collective learning.

Our study confirms the critical, but sometimes nevertheless underestimated role (e.g., Tett \& Burnett, 2003), that leaders play in knowledge sharing. In that sense, the first priority in constructing teams where knowledge sharing is a key requirement should be to choose leaders who have a learning goal orientation. Ideally, the team members who are selected will similarly have a learning orientation (first choice) or a performance approach orientation (second choice). Individuals who have a performance avoidance approach are unsuitable as team leaders and only acceptable (even then, somewhat marginally) as team members. Given that organizations are not populated just with ideal types (and leaving aside the recruitment of employees externally), understanding the respective goal orientations of both leaders and members will enable teams to be constructed that, because of appropriate fit between the two, have the greatest likelihood of knowledge sharing. So, for example, performance approach individuals can be excellent members of teams requiring knowledge sharing provided they do not have a performance avoidance leader.

Bearing in mind (i) that individual team members have propensities to be higher or lower on the three goal orientations (in other words, while they have an identifiable orientation, they have weaker latent propensities on the others) and (ii) that since individual goal orientations are amenable to change (DeShon \& Gillespie, 2005), attention should also be directed at developing desirable goal orientations in team members and creating an organizational culture and team climate that fosters a learning orientation in team members. In TAT terms, one of the ways in which this can be achieved is through facilitator cues from leaders (and, indeed, persons of power and authority above the team leaders in the organization), signaling and powerfully reinforcing the importance of knowledge sharing through both intrinsic and extrinsic rewards. The effect should not only be to encourage team members with a performance approach, but to provide a strong multiplicative effect in team members with a learning orientation.

\section{Limitations and Future Research Directions}

Both the limitations attaching to the way this study was conducted and the findings that emanated from it, provide the basis for future research. First, like similarly 
small-sample studies of goal orientation (e.g., Hirst et al., 2009; Janssen \& Van Yperen, 2004), caution must be used in generalizing these results. Replication of the study using a larger sample is necessary to verify our claims. Second, since knowledge sharing is only one aspect of team behavior, it would be worthwhile for future research to explore the relationship between the similarity of leadermember goal orientations and other outcome variables (e.g., innovation and creativity). Third, while this study has explored the pattern of leader-member goal orientations as a cross-level interplay leading to knowledge sharing behaviors, other interactive relationships might exist. The mechanisms underlying the formation and evolution of both individual and team goal orientations are interesting directions for future research. Fourth, while we have identified the goal orientations of team leaders as a key moderator, future research should examine the impact of other contextual effects on goal orientation-knowledge sharing relationships. For example, within the team, the effects of fellow team members' goal orientations might be important, the level of trust that team members have in their leader, should also be explored, especially in relation to the procedural and distributive fairness of rewards for knowledge sharing. Fifth, in TAT terms, in the wider context attention should be given to other social factors besides the leader, and to task and organizational factors (Dragoni, 2005). Though we controlled for some of those in our research design, others deserve empirical focus, including leader-member exchange relationships. Sixth, further attention needs to be directed to relationship between team leader and team member goal orientations at an even larger contextual level, for example, national culture. Future research should pay particular attention to the impact of such variables as: power distance (Hofstede, 2001); the strength of in-group and out-group relations (Chow, Deng, \& Ho, 2000; Gelfand, Bhawuk, Nishii, \& Bechtold, 2004) and norms of supervisor-subordinate reciprocity (Law, Wong, Wang, \& Wang, 2000); trust (Li, Bai, \& Xi, 2012); leadership traits other than goal orientation, such as consideration and initiating structure (Huang et al., 2008); and institutional factors such as enterprise type (Lau et al., 2002). Attention to these issues will help determine the extent to which the results in this study may have been influenced by cultural factors in the environment - China - in which this research was conducted. The question raised by Lu, Leung, and Koch (2006) then, as to whether cultural dynamics only affect the level of knowledge sharing or whether they also affect the processes underlying knowledge sharing remains open for further research.

\section{GONCLUSION}

Building on Trait Activation Theory, we examined the effect of cross-level interplays between team members' and their leaders' goal orientations (learning, performance approach, and performance avoidance) on knowledge sharing. The results showed that team members' goal orientation can be activated by situational cues, i.e., their team leader's goal orientation, when there is congruence between 
the goal orientation of leaders and members. This study has enriched the literature on goal orientation and knowledge sharing by illustrating team leaders' role in moderating the relationship between individual team members' goal orientation and their knowledge sharing behavior. It has also enhanced our understanding of the conditions under which knowledge sharing occurs among team members, and underlines the critical but sometimes underestimated role played by leaders in knowledge sharing.

\section{NOTE}

The authors would like to thank Tsinghua University Initiative Scientific Research Program (Grant No. 2015THZWSH07), and General Programme of National Natural Science Foundation of China (Grant No. 71172008).

[1] Using UCINET 6 software, ego-network density was calculated as the number of ties between the ego's direct-tie alters. This sum was then divided by the total number of possible ties; the maximum score occurs when every alter in the ego's direct-tie network is connected. Dense ego networks decrease the risk associated with exchanges and increase the efficiency of knowledge transfer. Ego-network density was used rather than centrality and network size because we were measuring knowledge sharing as a two-way phenomenon. This is particularly appropriate in (i) this cultural context (China) and (ii) this organizational context (highly educated professionals), in which it is expected that all parties will benefit from the exchange.

\section{REFERENGES}

Aiken, L. S., \& West, S. G. 1991. Multiple regression: Testing and interpreting interactions. Thousand Oaks, CA: Sage.

Argote, L. 2013. Organizational learning: Creating, retaining and transferring knozeledge (2nd ed.). New York: Springer.

Avolio, B. J., \& Bass, B. M. 1995. Individual consideration viewed at multiple levels of analysis: A multi-level framework for examining the diffusion of transformational leadership. The Leadership Quarterly, 6(2): 199-218.

Bartol, K. M., \& Srivastava, A. 2002. Ecncouraging knowledge sharing: The role of organizational reward systems. Journal of Leadership and Organization Studies, 9(1): 64-76.

Brass, D. J. 1985. Men's and women's networks: A study of interaction patterns and influence in an organization. Academy of Management Journal, 28(2): 327-343.

Bryant, S. E. 2003. The role of transformational and transactional leadership in creating, sharing and exploiting organizational knowledge. Journal of Leadership \& Organizational Studies, 9 (4): $32-44$.

Bunderson, J. S., \& Reagans, R. E. 2011. Power, status, and learning in organizations. Organization Science, 22(5): 1182-1194.

Bunderson, J. S., \& Sutcliffe, K. M. 2003. Management team learning orientation and business unit performance. Journal of Applied Psychology, 88(3): 552-560.

Burkhardt, M. E. 1994. Social interaction effects following a technological change: A longitudinal investigation. Academy of Management Journal, 37(4): 869-898.

Button, S. B., Mathieu, J. E., \& Zajac, D. M. 1996. Goal orientation in organizational research: A conceptual and empirical foundation. Organizational Behavior and Human Decision Processes, 67(1): 26-48.

Gellar, D. F., Stuhlmacher, A. F., Young, S. K., \& Fisher, D. M. 2011. Trait goal orientation, selfregulation, and performance: A meta-analysis. Journal of Business and Psychology, 26(4): 467-483.

Chen, G., \& Kanfer, R. 2006. Toward a systems theory of motivated behavior in work teams. Research in Organizational Behavior, 27: 223-267. 
Chow, C. W., Deng, F. J., \& Ho, J. L. 2000. The openness of knowledge sharing within organizations: A comparative study of the United States and the People's Republic of China. Journal of Management Accounting Research, 12(1): 65-95.

Darnon, C., Harackiewicz, J. M., Butera, F., Mugny, G., \& Quiamzade, A. 2007. Performanceapproach and performance-avoidance goals: When uncertainty makes a difference. Personality and Social Psychology Bulletin, 33(6): 813-827.

De Dreu, C. K. W., Nijstad, B. A., \& Van Knippenberg, D. 2008. Motivated information processing in group judgment and decision making. Personality and Social Psychology Revieze, 12 (1): $22-49$.

Deshon, R. P., \& Gillespie, J. Z. 2005. A motivated action theory account of goal orientation. Joumal of Applied Psychology, 90(6): 1096-1 127.

Donovan, J. J., Bateman, T. S., \& Heggestad, E. D. 2013. Individual differences in work motivation: Current directions and future needs. In N. Christiansen \& R. P. Tett (Eds.), Handbook of personality at work: 101-128. New York: Routledge.

Dragoni, L. 2005. Understanding the emergence of state goal orientation in organizational work groups: The role of leadership and multilevel climate perceptions. Joumal of Applied Psychology, 90(6): 1084-1095.

Dragoni, L., \& Kuenzi, M. 2012. Better understanding work unit goal orientation: Its emergence and impact under different types of work unit structure. Joumal of Applied Psychology, 97(5): 1032-1048.

Dweck, C. 1999. Self-theories: Their role in motivation, personality and development. Philadelphia: Psychology Press.

Dweck, C. S. 1986. Motivational processes affecting learning. American Psychologist, 41(10): 1040-1048.

Elliot, A. J., \& Church, M. A. 1997. A hierarchical model of approach and avoidance achievement motivation. Journal of Personality \& Social Psychology, 72(1): 218-232.

Elliot, A. J., \& McGregor, H. A. 2001. A 2 X 2 achievement goal framework. Journal of Personality and Social Psychology, 80(3): 501-519.

Everett, J. E., \& Stening, B. W. 1980. Intercultural interpersonal perceptions: A study of Japanese and Australian managers. Japanese Psychological Research, 22(1): 42-47.

Foss, N. J., Husted, K., \& Michailova, S. 2010. Governing knowledge sharing in organizations: Levels of analysis, governance mechanisms, and research directions. Journal of Management Studies, 47(3): 455-482.

Gelfand, M.J., Bhawuk, D. P., Nishii, L. H., \& Bechtold, D. J. 2004. Individualism and collectivism. In R. J. House, P. J. Hanges, M. Javidan, P. W. Dorfman, \& V. Gupta (Eds.), Culture, leadership, and organizations: The GLOBE Study 62: 437-512.

George, J. M., \& Jing, Z. 2007. Dual tuning in a supportive context: Joint contributions of positive mood, negative mood, and supervisory behaviors to employee creativity. Academy of Management Journal, 50(3): 605-622.

Gong, Y., Huang, J.-C., \& Farh, J.-L. 2009. Employee learning orientation, transformational leadership, and employee creativity: The mediating role of employee creative self-efficacy. Academy of Management Journal, 52(4): 765-778.

Gong, Y., Kim, T.-Y., Lee, D.-R., \& Zhu, J. 2013. A multilevel model of team goal orientation, information exchange, and creativity. Academy of Management Joumal, 56(3): 827-851.

Gray, P. H., \& Meister, D. B. 2004. Knowledge sourcing effectiveness. Management Science, 50 (6): $821-834$.

Hansen, M. T. 1999. The search-transfer problem: The role of weak ties in sharing knowledge across organization subunits. Administrative Science Quarterly, 44(1): 82-111.

Hirst, G., Van Knippenberg, D., Chen, C.-H., \& Sacramento, C. A. 2011 . How does bureaucracy impact individual creativity? A cross-level investigation of team contextual influences on goal orientation-creativity relationships. Academy of Management Joumal, 54(3): 624-641.

Hirst, G., Van Knippenberg, D., \& Zhou, J. 2009. A cross-level perspective on employee creativity: Goal orientation, team learning behavior, and individual creativity. Academy of Management Journal, 52(2): 280-293.

Hofstede, G. 2001. Culture's consequences ( $2^{\text {nd }}$ ed.). Thousand Oaks, CA: Sage Publications.

Huang, Q., Davison, R. M., Liu, H., \& Gu, J. 2008. The impact of leadership style on knowledgesharing intentions in China. Journal of Global Information Management, 16(4): 67-91.

Huber, G. P. 1991. Organizational learning: The contributing processes and the literatures. Organization Science, 2(1): 88-115. 
Ipe, M. 2003. Knowledge sharing in organizations: A conceptual framework. Human Resource Development Revieze, 2(4): 337-359.

James, L. R., Demaree, R. G., \& Wolf, G. 1984. Estimating within-group interrater reliability with and without response bias. Journal of Applied Psychology, 69(1): 85-98.

Janssen, O., \& Prins, J. 2007. Goal orientations and the seeking of different types of feedback information. Joumal of Occupational and Organizational Psychology, 80(2): 235-249.

Janssen, O., \& Van Yperen, N. W. 2004. Employees' goal orientations, the quality of leader-member exchange, and the outcomes of job performance and job satisfaction. Academy of Management Journal, 47(3): 368-384.

Kaplan, A., \& Maehr, M. 2007. The contributions and prospects of goal orientation theory. Educational Psychology Revieze, 19(2): 141-184.

Kristof-Brown, A. L., \& Stevens, G. K. 2001. Goal congruence in project teams: Does the fit between members' personal mastery and performance goals matter? Journal of Applied Psychology 86(6): 1083-1095.

Labianca, G., Brass, D. J., \& Gray, B. 1998. Social networks and perceptions of intergroup conflict: The role of negative relationships and third parties. Academy of Management Journal, 41(1): 55-67.

Lau, G.-M., Tse, D. K., \& Zhou, N. 2002. Institutional forces and organizational culture in China: Effects on change schemas, firm commitment and job satisfaction. Journal of International Business Studies, 33(3): 533-550.

Law, K. S., Wong, C.-S., Wang, D., \& Wang, L. 2000. Effect of supervisor-subordinate guanxi on supervisory decisions in China: An empirical investigation. The International Journal of Human Resource Management, 11(4): 751-765.

Leonard, D., \& Sensiper, S. 1998. The role of tacit knowledge in group innovation. California Management Revieze, 40(3): 112-132.

Li, P. P., Bai, Y., \& Xi, Y. 2012. The contextual antecedents of organizational trust: A multidimensional cross-level analysis. Management and Organization Revieze, 8(2): 371-396.

Liao, H., \& Chuang, A. 2004. A multilevel investigation of factors influencing employee service performance and customer outcomes. Academy of Management Journal, 47(1): 41-58.

Lu, L., Leung, K., \& Koch, P. T. 2006. Managerial knowledge sharing: The role of individual, interpersonal, and organizational factors. Management and Organization Revieze, 2(1): 15-41.

Marsden, P. V. 1990. Network data and measurement. Annual Revieze of Sociology, 16: 435-463.

Matzler, K., \& Mueller, J. 2011. Antecedents of knowledge sharing - Examining the influence of learning and performance orientation. Joumal of Economic Psychology, 32(3): 317-329.

Nonaka, I., \& Takeuchi, H. 1995. The knowledge-creating company: How Japanese companies create the dynamics of innovation. New York: Oxford University Press.

Nonaka, I., \& Von Krogh, G. 2009. Tacit knowledge and knowledge conversion: Controversy and advancement in organizational knowledge creation theory. Organization Science, 20(3): 635-652.

Payne, S. C., Youngcourt, S. S., \& Beaubien, J. M. 2007. A meta-analytic examination of the goal orientation nomological net. Journal of Applied Psychology, 92(1): 128-150.

Perry-Smith, J. E. 2006. Social yet creative: The role of social relationships In facilitating individual creativity. Academy of Management Joumal, 49(1): 85-101.

Phillips, A. S., \& Bedeian, A. G. 1994. Leader-follower exchange quality: The role of personal and interpersonal attributes. Academy of Management Journal, 37(4): 990-1001.

Porath, C. L., \& Bateman, T. S. 2006. Self-regulation: From goal orientation to job performance. Journal of Applied Psychology, 91(1): 185-192.

Raudenbush, S., Bryk, A., Cheong, Y. F., \& Congdon, R. 2004. HLM 6: Hierarchical and Nonlinear Modeling [computer software], Lincolnwood, IL: Scientific Software International.

Reagans, R., \& Mcevily, B. 2003. Network structure and knowledge transfer: The effects of cohesion and range. Administrative Science Quarterly, 48(2): 240-267.

Shang, Y. F., Fu, P. P., \& Chong, M. 2012. Relational power in the Chinese context. In X. Huang \& M. H. Bond (Eds.), Handbook of Chinese organizational behavior: 436-448. Cheltenham, UK: Edward Elgar.

Shin, S. J., \& Zhou, J. 2007. When is educational specialization heterogeneity related to creativity in research and development teams? Transformational leadership as a moderator. Journal of Applied Psychology, 92(6): 1709-1721. 
Siemsen, E., Roth, A. V., Balasubramanian, S., \& Anand, G. 2009. The influence of psychological safety and confidence in knowledge on employee knowledge sharing. Manufacturing \& Service Operations Management, 11(3): 429-447.

Skaalvik, E. M. 1997. Self-enhancing and self-defeating ego orientation: Relations with task and avoidance orientation, achievement, self-perceptions, and anxiety. Journal of Educational Psychology, 89(1): 71-81.

Srivastava, A., Bartol, K. M., \& Locke, E. A. 2006. Empowering leadership in management teams: Effects on knowledge sharing, efficacy, and performance. Academy of Management Journal, 49(6): 1239-1251.

Swift, M., Balkin, D. B., \& Matusik, S. F. 2010. Goal orientations and the motivation to share knowledge. Journal of Knozeledge Management, 14(3): 378-393.

Tett, R., \& Murphy, P. 2002. Personality and situations in co-worker preference: Similarity and complementarity in worker compatibility. Journal of Business and Psychology, 17(2): 223-243.

Tett, R. P., \& Burnett, D. D. 2003. A personality trait-based interactionist model of job performance. Journal of Applied Psychology, 88(3): 500-517.

Tett, R. P., \& Guterman, H. A. 2000. Situation trait relevance, trait expression, and cross-situational consistency: Testing a principle of trait activation. Journal of Research in Personality, 34(4): 397-423.

Tett, R. P., Simonet, D. V., Walser, B., \& Brown, C. 2013. Trait activation theory: Applications, developments, and implications for person-workplace fit. In N. Christiansen \& R. P. Tett (Eds.), Handbook of personality at work: 71-100. New York: Routledge.

VandeWalle, D. 1997. Development and validation of a work domain goal orientation instrument. Educational and Psychological Measurement, 57(6): 995-1015.

Von Hippel, E. 1994. 'Sticky information' and the locus of problem solving: Implications for innovation. Management Science, 40(4): 429-439.

Von Krogh, G., Nonaka, I., \& Rechsteiner, L. 2012. Leadership in organizational knowledge creation: A review and framework. Journal of Management Studies, 49(1): 240-277.

Wang, S., \& Noe, R. A. 2010. Knowledge sharing: A review and directions for future research. Human Resource Management Revieze, 20: 115-131.

Watson, A. M., Thompson, L. F., Rudolph, J. V., Whelan, T. J., Behrend, T. S., \& Gissel, A. L. 2013. When big brother is watching: Goal orientation shapes reactions to electronic monitoring during online training. Joumal of Applied Psychology, 98(4): 642-657.

Yeo, G., Loft, S., Xiao, T., \& Kiewitz, C. 2009. Goal orientations and performance: Differential relationships across levels of analysis and as a function of task demands. Journal of Applied Psychology, 94(3): 710-726.

Zander, U., \& Kogut, B. 1995. Knowledge and the speed of the transfer and imitation of organizational capabilities: An empirical test. Organization Science, 6(1): 76-92.

Jiamin Zhang (zhangjm.13@sem.tsinghua.edu.cn) is a lecturer in management in the Department of Management and Marketing at the University of Melbourne. She received her $\mathrm{PhD}$ in Management from the School of Economics and Management at Tsinghua University. Using the lenses of organizational economics and social networks, she studies the role of human, financial, and social capital in technology-focused entrepreneurial ventures. She has also examined the theoretical dilemma of knowledge sharing and knowledge leakage in firms' R\&D alliance networks, as well as the implications for innovation management.

Yi Wang (wangyi@sem.tsinghua.edu.cn) is an Associate Professor in the School of Economics and Management at Tsinghua University. He carries out field-based research on the role of capabilities in corporate innovation management. He has examined how sticky knowledge transfer contributes to capability building and enhancing, how core competences evolve along with 
corporate growth, and how corporate innovation capabilities co-evolve with sectoral systems of innovation. He received his $\mathrm{PhD}$ in Management from Zhejiang University.

Marina Yue Zhang (myzhang@swin.edu.au) is an Associate Professor at Swinburne Business School, Swinburne University of Technology. She holds a bachelor's degree in biological sciences from China's Peking University, and an MBA and $\mathrm{PhD}$ from the Australian National University. Prior to joining Swinburne, she held positions in the University of New South Wales in Australia and Tsinghua University in China, as well as senior management positions at IBM and Ericsson. Her research fields cover disruptive innovation, emerging industry, high-tech entrepreneurship, business model innovation, and catch-up of latecomers in emerging markets.

Manuscript received: October 7, 2016

Final version accepted: May 8, 2018 (number of revisions - 3)

Accepted by:

Senior Editor Mooweon Rhee 